\title{
Challenges for Mental Health Professionals in the 21st Century
}

\author{
Eduardo J. R. Santos \\ Institute of Cognitive Psychology, Human and Social Development, University of Coimbra, Portugal \\ *Corresponding author: Eduardo J. R. Santos, Institute of Cognitive Psychology, Human and Social Devel- \\ opment, University of Coimbra, Portugal, E-mail: santoseduardo56@gmail.com
}

Received Date: 24 September, 2018; Accepted Date: 26 September, 2018; Published Date: 01 October, 2018

In times of global and regional crises, the phenomena we see on a daily basis are serious sources of disturbance of mental health, causing devastating effects on the behavior of individuals and groups. The United Nations Development Program (UNDP) outlines in its many studies, publications and initiatives a reliable picture of the state of the situation. Today we need more and more empowered lives and to develop resilient communities.

We know that in the last decades the mental health sciences have evolved in the sense of tracing universal strategies, although culturally situated, to promote personal and collective well-being. However, we continue to see deprivations, inequalities and extremisms as serious threats to the mental health of people. For these reasons, it is essential to face the challenges that the 21 st century brings us. And do it with rigor and responsibility.

It is not our intention to draw up a sadly long list of situations which have implications for mental illness, such as hunger and poverty, gender discrimination issues or the problem of migrants and refugees. We just want to alert to the need to perform realistic and scientifically and clinically reasoned analyzes and assessments, and given the complexity of these phenomena, the urgency in organizing interdisciplinary interventions.

We must have hope in our ability to overcome these challenges, and transmit that hope to those who seek us in the search for support for their suffering. As Editor-in-Chief of this new scientific publication this is my message for our second issue. 


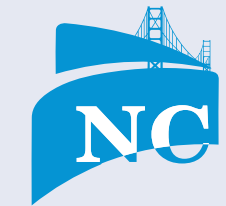 \\ OPONACCES RUEULCATLONS \\ submit your manuscripts at \\ www. norcaloa.com}

